\title{
CABARÉ DA SANTA: UM PROJETO TEATRAL LUSO-BRASILEIRO, COM DAGOBERTO FELIZ E JORGE LOURACO FIGUEIRA
}

\section{CABARÉ DA SANTA: A PORTUGUESE-BRAZILIAN PROJECT, WITH DAGOBERTO FELIZ AND JORGE LOURACO FIGUEIRA}

http://dx.doi.org/10.11606/issn.2175-3180.v12i23p272-290

Por Helderson Mariani Pires ${ }^{\mathrm{I}}$

RESUMO

Entrevistas com o encenador Dagoberto Feliz e o dramaturgo Jorge Louraço Figueira, sobre o projeto teatral Cabaré da Santa, ocorrido em 2008, com os grupos teatrais Folias, de São Paulo, Brasil, e o Teatrão, de Coimbra, Portugal. O projeto teve lugar na comemoração dos cem anos da chegada da família real portuguesa em terras brasileiras.

\section{PALAVRAS-CHAVE}

Teatro luso-brasileiro; Dramaturgia; Encenação.

\section{ABSTRACT}

Interviews with the director Dagoberto Feliz and the playwright Jorge Louraço Figueira, about the 2008 theatrical project Cabaré da Santa, which has held with the Brazilian group Folias (São Paulo) and the Portuguese group Teatrão (Coimbra). The project occurred on the celebrations of the 100th anniversary of the Portuguese Royal Family's arrival on Brazil.

\section{KEYWORDS}

Portuguese-Brazilian theatre; Dramaturgy; Performance.

I Pontifícia Universidade Católica, São Paulo, Brasil. 
A Reinaldo Maia, in memoriam

\section{APRESENTAÇ̃̃ES INTRODUTÓRIAS}

Jorge Louraço é dramaturgo e escreveu Cassandra de Balaclava (Cão Danado, 2013), Teleganza (Nova Europa, 2011), Éxodos (Folias, São Paulo, 2008), Xmas qd Kiseres* (O Teatrão, 2002) e O Espantalho Teso (TNSJ, 2001); dirigiu Contame Como É, de Pedro Marques, Jorge Palinhos e Sandra Pinheiro (O Teatrão, 2014) e Pequena História Trágico-Marítima (TAGV, 2012); traduziu Cidadania, de Mark Ravenhill, Senti um Vazio, de Lucy Kirkwood, Onde É que Esconderam as Respostas, dos Third Angel, e Ricardo III, de Shakespeare; fez a Oficina de Escrita Teatral de A. Mercado no TNSJ, o Seminário Traverse Theatre nos Artistas Unidos, a Residência Internacional do Royal Court Theatre, e o Seminário de Escrita Teatral de J. S. Sinisterra no TNDM II; é doutorando em Estudos Artísticos na Universidade de Coimbra (bolseiro da FCT), dramaturgo residente do Teatrão (Coimbra), docente da ESMAE e crítico de teatro do jornal Público.

Ator, diretor musical e encenador, Dagoberto Feliz participa do Grupo Folias desde sua fundação. Sua trajetória conta, ao todo, com mais de 95 espetáculos. Já recebeu alguns dos principais prêmios da cena brasileira. Por exemplo, em 2016, foi contemplado pelo prêmio APCA de Melhor Espetáculo Infantil para Chiquita Bacana no Reino das Bananas, onde trabalhou como encenador; de melhor direção de espetáculo teatral musical da Arte Qualidade, por Godspell; em 2013, levou o Prêmio APCA de melhor direção, por Folias Galileu; e, em 2005, o Prêmio Shell de direção musical por El Día Que me Quieras.

O Folias é um grupo teatral que dispõe de sua sede/teatro, o Galpão do Folias, na Rua Ana Cintra, bairro de Santa Cecília, região central de São Paulo, Brasil. É um teatro projetado pelo arquiteto e cenógrafo J.C. Serroni que está aberto ao público há 20 anos. Em 2020, o Grupo comemora 23 anos de existência, com reconhecimento de público e crítica e com aproximadamente 50 prêmios, entre eles: Prêmio Shell, Prêmio APCA, Prêmio Molière, incluindo a participação e representação do Brasil no 
FITEI, Festival Internacional de Expressão Ibérica (Porto/Portugal), no MITE - Mostra Internacional de Teatro (Lisboa/Portugal). No final dos anos 90, Marco Antonio Rodrigues e Reinaldo Maia (um dos dramaturgos do Cabaré da Santa), que trabalhavam juntos na Funarte, resolvem montar uma peça que mostrasse os bastidores do teatro. Deste processo surgiu o Verás que tudo é mentira (1995), espetáculo de rua que se tornou o embrião do que seria o grupo futuramente, neste momento estava Dagoberto Feliz fazendo direção musical. Desde então, muitos foliães têm passado por este lugar, somando 35 espetáculos para os mais diversos públicos, utilizando da imaginação e da arte para refletir sobre problemas e angústias concretas da nossa sociedade.

O Teatrão é uma companhia profissional de teatro fundada em 1994 por Manuel Guerra, que existe para pensar, desafiar e inspirar a contemporaneidade, procurando intervir no cotidiano das comunidades onde atua, contribuindo para que a arte seja reconhecida como prática essencial das sociedades. Desde o princípio, contou com o apoio da Secretaria Estadual de Cultura, criando uma rede de trabalho com as comunidades escolares e tendo sua sede/teatro na Oficina Municipal do Teatro, Rua Pedro Nunes, Qta da Nora, na cidade de Coimbra, Portugal. A sua atividade destaca-se devido a uma oferta ampla e permanente, garantida pela diversidade, que inclui peças para vários tipos de público; cria espetáculos que tanto revisitam os autores clássicos como exploram dramaturgias originais, como foi o caso do Cabaré da Santa. O Teatrão distingue-se por ser uma companhia de atores-pedagogos, empenhada em partilhar os conhecimentos sobre as artes do espetáculo com a população em geral, através da criação artística, em especial nas subdisciplinas da interpretação, escrita dramática e encenação. Até agora tem no seu currículo a montagem de 87 espetáculos teatrais.

\section{ENTREVISTA COM JORGE LOURAÇO FIGUEIRA, o DRAMATURGO:}

HM: Como surgiu a ideia inicial do projeto Cabaré da Santa? Você, como dramaturgo, participou da elaboração do projeto? Quais foram os principais objetivos da dramaturgia?

JL: Participei, sim, a concepção do projeto foi partilhada. A peça resulta de um processo de conhecimento mútuo. A primeira vez que ouvi falar no 
Folias foi quando o Antonio Mercado nos falou, entusiasmado, da montagem de Otelo. Me lembro muito bem de ver Mercado, que tinha chegado de uma viagem a São Paulo, com o programa do espetáculo na mão, no jardim em frente à Oficina Municipal do Teatro, falando do grupo. Isto deve ter sido em 2003. Em 2004 eu próprio pude ver essa montagem, no Galpão do Folias. Depois, Marco Antonio Rodrigues veio trabalhar em Coimbra, na ESEC e no Teatrão, e Otelo se apresentou em Lisboa e no Porto, em 2006. Então, a cumplicidade entre O Teatrão, de Coimbra, e o Folias começou nessa época e continua. A ideia surgiu porque era frequente conversarmos sobre a história de Portugal e Brasil, sobre a herança comum dos dois países, as semelhanças e as diferenças, e as impropriedades e paradoxos da relação colonial. Aproximava-se o centenário da chegada da corte portuguesa ao Rio de Janeiro e achámos que podia ser interessante revisitar esse episódio singular. Era uma época em que, além do mais, o teatro de grupo de São Paulo criava a partir do estudo da formação do Brasil, ou seja, a partir das obras de Buarque de Holanda, Antonio Candido, Roberto Schwarz, entre outros; ou ainda a partir dos trabalhos de Artur Azevedo e de Machado de Assis, tentando entender o país e a cidade. E o papel dos portugueses vinha sempre à baila. A parceria que se estava a criar com Portugal era também ela cheia de contradições e alguém teve a intuição de que havia ali matéria para brincar. De resto, vinha aí também um aniversário do Folias e o grupo queria assinalar isso com algum tipo de festa teatral. Daí Cabaré da Santa, que é Santa Cecília, claro. O Marco deve ter tido a ideia de fazer um espetáculo cómico e musical, até porque tinham vindo de El día que me quieras, de Cabrujas, onde esses aspectos estavam muito presentes. Acho que o Maia se lembrou do livro História do Brasil pelo Método Confuso. E começamos a alinhar histórias e a trocar ideias, até chegar a uma situação, personagens, enredo. Os objetivos eram revisitar a história comum aos dois países, brincar com as diferenças linguísticas e outras, celebrar a cumplicidade sem ocultar as contradições. A grande ambição era que em cena estivesse um elenco misto, isto é, de portugueses e brasileiros, coisa que não se veio a concretizar. Apenas Dagoberto acabou por viajar para Portugal e encenar o espetáculo cá. Aliás, a estreia da versão portuguesa marca não o aniversário do Teatrão, mas o início da ocupação do atual espaço, o que reverberou na dramaturgia. Uns anos mais tarde, numa viagem do Teatrão ao Brasil, fez-se uma espécie de sarau onde alguns dos atores fizeram uma cena em conjunto, creio, mas 
talvez tenha sido de outro espetáculo dirigido pelo Dagoberto, Single Singers Bar.

HM: Dentro do Cabaré da Santa, há a presença de dois dramaturgos: Reinaldo Maia, no Brasil; e você, em Portugal. Dentro dessas condições, como foi a escritura do texto dramatúrgico?

JL: Começamos por definir uma história, a da chegada de um grupo de portugueses a um velho cabaré do centro de São Paulo, através de um túnel no tempo e no espaço, que permitia todos os anacronismos. Depois fomos avançando esboço a esboço: Maia escrevia uma parte, eu escrevia a partir daí e revia alguma coisa do que já estava, devolvia, ele escrevia mais um pedaço e fazia a revisão do que eu tinha escrito, e então me mandava de novo. Foi muito simples, na verdade. Aos poucos a forma foi sendo definida. A finalização foi feita já durante os ensaios, porém, com a música, o elenco, etc, a serem levados em consideração na versão final.

HM: Quais foram os principais objetivos contemplados pela dramaturgia?

JL: Havia um objetivo que era brincar com as palavras diferentes, em Portugal e no Brasil, usadas para as mesmas coisas, que acho que não desenvolvemos tanto quanto queríamos. O grande objetivo era satirizar a importância que as entidades oficiais atribuem a si mesmas, em especial no que diz respeito às relações Portugal-Brasil, e as meias-verdades em que assentam as comemorações oficiais de datas comuns à história de Portugal e Brasil, como era o caso da chegada da corte ao Brasil, denunciando os interesses egoístas e ridículos por trás das frases pomposas e das aparências imperiais. Esse objetivo foi conseguido. No fundo, queríamos tirar um sarro de nós próprios, das expectativas que os cidadãos dos dois países têm uns dos outros. A emigração de Brasileiros para Portugal e para a Europa tinha crescido muito nesses anos, como "nunca antes" na história, e o turismo de portugueses no Brasil também tinha aumentado, então havia muita oportunidade para rir das ideias feitas, das lendas e dos mitos.

HM: Como foi criada a narrativa dentro dessa dramaturgia? 
JL: Nós realmente usámos todos os ingredientes que havia na cozinha: Mendes Fradique, autor pseudónimo da História do Brasil pelo Método Confuso, inversão de Fradique Mendes, de Eça de Queirós; a Mariquinhas, da famosa casa de raparigas, personagem de uma série de fados cantados por Amália; Rafael, o português da Utopia, de Thomas More; e outras figuras heroicas e míticas, de Bento Teixeira ao abade de Trancoso... de modo que em cena estava um panteão muito diversificado de figuras, a quem aconteciam coisas aparentemente sem nexo, um pouco como a lição de história do Auto dos 99\% ou o Samba do Crioulo Doido. Apanhadas numa encruzilhada, as personagens tentavam enganar-se umas às outras para sobreviver. Os brasileiros prometiam aos portugueses um eldorado, com centro no Cabaré, que viria a ser um cassino de nível mundial. Os portugueses, porém, queriam fundar um Sexto Império, passada que tinha sido a oportunidade do Quinto. $\mathrm{O}$ argumento ecoa um pouco o de $O$ Corsário do Rei, de Boal, ou o de O Bilontra, de Azevedo, com o Brasil sendo posto à venda e oferecido a turistas e empresários, entre os quais se encontra um imortal D. João VI. Mas nada funciona como previsto. No fim, Santa Cecília intervém, despachando toda a gente para povoar e "retrocolonizar" Portugal. Como se canta no final, parodiando Chico Buarque, "Ai, esta terra ainda vai rever o seu perfil / Ainda vai tornar-se... o vigésimo oitavo estado do Brasil". O que fizemos foi criar uma alegoria para tratar o tema da colonização mal feita, por um lado, e da inversão dos papéis de metrópole e colónia que ocorreu em 1807, por outro. O desajuste entre a imagem que os portugueses e os brasileiros têm de si mesmos e o destino de um e outro país, respetivamente, deram matéria-prima para criar as figuras e as peripécias.

HM: Hoje, depois de mais de dez anos e com duas montagens realizadas pelos grupos Folias e Teatrão, qual a sua avaliação do texto dramatúrgico? E qual sua avaliação geral do projeto?

$J L:$ A peça continua sendo muito divertida e qualquer grupo a poderia montar, embora haja muita coisa que se deve à encenação e direção musical do Dagoberto Feliz e aos elencos de cada país que não está no texto, pelo menos não à primeira vista, que eu não distingo muito da dramaturgia, porque foi um projeto feito de um modo muito orgânico, e que talvez precisasse de ser recuperado através da visualização dos registos. Inclusive 
deixo aqui um apelo aos leitores para que aproveitem a efeméride dos 200 anos da independência e montem a peça. $\mathrm{O}$ meu balanço tem a ver com $\mathrm{o}$ balanço da história, porém. Há dez anos, a brincadeira com o povoamento de Portugal por brasileiros era uma brincadeira simbólica. Hoje em dia, é real a renovação das artes e das ciências portuguesas por pessoas migradas do Brasil. Pensando bem, sempre foi assim, ao longo da história, já que a colónia fazia parte da vida da metrópole. Infelizmente, essa migração deve-se a um renovar do projeto colonialista no Brasil, às mãos de descendentes de europeus, o que também não é novidade. A mistura que propúnhamos como saída, no Cabaré da Santa, tem aspectos negativos, nomeadamente o risco de ocultar as centenas de anos de discriminação, segregação e extermínio, mas ainda me parece a melhor saída para, no futuro, nos vacinar contra a utopia colonial.

HM: Como foi ver o seu texto encenado por um grupo brasileiro? Você, enquanto estrangeiro, enxerga na montagem realizada pelo Folias algo que remeta a um certo sentido de "brasilidade"? E o grupo português, que montou depois, você acredita que foi impregnado por esta "brasilidade" em alguma medida?

JL: As duas montagens criticavam a brasilidade e a portugalidade, usando todos os estereótipos cómicos das caricaturas, do teatro de revista, da rádio e da TV, etc. Diria que, sem esse sentido de brasilidade e portugalidade, e sem um sentido crítico e uma noção de ridículo, essas montagens nunca teriam sido feitas, nem a peça escrita. $\mathrm{O}$ bom é que depois de nos rirmos uns dos outros, nos reencontramos na nossa finitude e irrelevância, e nos reconhecemos como iguais, para lá dessas imagens de Portugal e do Brasil. O texto não era só meu, nem só do Maia, mas de toda a equipe, é certamente muito de ambos os elencos, e dos dois grupos, de modo geral. A ideia sempre foi unir estes dois grupos de artistas, que vinham colaborando em vários espetáculos e assistindo o trabalho uns dos outros, pelo que não consigo até hoje desligar o texto do processo.

\section{ENTREVISTA COM DAGOBERTO FELIZ, O ENCENADOR:}

HM: Dagoberto Feliz, me lembro bem que tive a oportunidade de acompanhar de perto a concretização do projeto Cabaré da Santa, aqui no Brasil, em São Paulo, com o Grupo Folias; e em Coimbra, Portugal, com o 
Grupo Teatrão, o que foi para mim um grande aprendizado. Mas vamos começar falando, inicialmente, sobre a ideia e a elaboração do projeto. Quais foram os objetivos dos dois grupos com esse trabalho em conjunto? E como foi a sua indicação para fazer a encenação das duas montagens, aqui no Brasil e em Portugal?

DF: Bem... o Folias, nosso grupo aqui de São Paulo, alguns anos antes de 2008, já mantinha uma relação artística com o Teatrão, de Portugal, principalmente através de algumas direções de espetáculos realizadas, na Oficina Municipal de Teatro em Coimbra, pelo diretor Marco Antonio Rodrigues, que nessa época estava diretamente ligado ao Folias. Essa parceria artística que se delineava entre os dois grupos apontou o caminho de duas possíveis montagens, misturando-se os respectivos núcleos artísticos. A ideia original era que fossem feitas duas montagens simultâneas ou sucessivas com elenco composto por atores portugueses em São Paulo, e atores brasileiros em Portugal. Isso provocaria uma integração não só artística como também de convivência. Alguns atores do Folias permaneceriam em Coimbra para a execução do projeto; e alguns atores do Teatrão estariam em São Paulo com o mesmo propósito.

É importante dizer também que a provocação artística surgiu da "comemoração" de 200 anos da saída (ou fuga) e da chegada da Família Real e da Corte Portuguesa ao Brasil, esse foi o mote provocador para os autores Jorge Louraço e Reinaldo Maia. Colocar os pontos de vista português e brasileiro juntos com opiniões críticas, às vezes antagônicas, às vezes similares, eis um dos desafios. Essa era a ideia original do projeto, que infelizmente teve que ser adaptada, uma vez que os recursos financeiros para cobrir os custos para tal empreitada não foram suficientes. Em algum momento, por orçamento, vimo-nos obrigados a reduzir a que a Direção fosse brasileira em ambas as montagens e a Direção Musical em Portugal fosse feita por Filipe Costa, ator e músico do Teatrão na época. Como, desde o início do Folias, estava na maioria dos espetáculos, ligado à parte musical, além de ator e diretor, resolveu-se que a direção de ambos os espetáculos seria eu quem ficaria responsável.

HM: O texto dramatúrgico foi escrito por um brasileiro e um português. Você acompanhou a escritura desse texto? Como foram suas conversas 
com os dois autores? E, principalmente, quais foram suas impressões pessoais iniciais, como encenador, quando recebeu a dramaturgia pronta?

DF: Não acompanhei diretamente o início da escrita do texto do Reinaldo Maia (Folias) e do Jorge Louraço (Teatrão). Sei que o Maia e Jorge conversaram bastante e iam produzindo o material dramatúrgico, às vezes separadamente, cada qual em seu país, e às vezes, presencialmente. Cabe lembrar que estávamos em 2007 e 2008, e que os recursos tecnológicos eram outros. Neste momento pandêmico em que, infelizmente e/ou felizmente, os contatos via internet já viraram cotidianos, não era essa a realidade naquele momento histórico. Eram outros tempos. Em alguns momentos o Jorge teve a oportunidade de vir ao Brasil; e ele e o Maia se encontravam "presencialmente" - esse termo tinha outro significado do que o atual. Quando isso não era possível, sei que um mandava o texto para o outro; e assim foi-se formando a forma dramatúrgica final, ou pelo menos, o primeiro texto que foi apresentado para ambas as Companhias.

$\mathrm{O}$ texto originalmente chamava-se Cabaré da Liberdade, em um apontamento das discussões dos autores. Em um outro encontro com o Maia chegou-se ao nome Cabaré da Santa por aproximação do Bairro de Santa Cecília (onde se localiza o Galpão do Folias) e à própria Santa Cecília, que surge como um "deus ex-machina", quase na parte final do texto.

E assim ficou.

Como impressões sobre a "primeira versão do texto" apresentada, ficava clara a intenção de ambos os autores, colocando toda a trama passada em um cabaré de duvidosa reputação; a vontade de que os assuntos tidos como sérios e importantes pela maioria dos eventos propostos institucionalmente pelos países irmãos fosse colocada, ironicamente, em xeque. Fazer com que o público, brasileiro ou português, que viesse a assistir, refletisse crítica e divertidamente, sobre os fatos históricos, exaustivamente, na época, colocados nas mídias.

HM: No texto dramatúrgico você era capaz de dizer o que tinha sido escrito por um e por outro autor? Quais as facilidades e desafios que a dramaturgia trouxe para a sua encenação?

DF: Às vezes sim, às vezes não. Claro que o sotaque, expressões, construções gramaticais e situações cotidianas culturais escancaravam 
quando eram as palavras de um dos autores, bem como as próprias personagens portuguesas, brasileiras, indígenas ou ainda de outras origens; mas isso, no decorrer do texto, também acabava se misturando, provocando uma confusão de origem da escrita. Essa também era a intenção original da proposição do projeto. Onde os dois pensamentos, de dois povos que, embora próximos, se misturavam e se distinguiam.

O formato de cabaré, que está contido no conceito da ESTÉTICA POPULAR, com seus quadros sucessivos, já permitiam através da escrita original do texto, uma liberdade para a encenação. Por prática de ofício, desde o Grupo Gextus, da Faculdade Católica de Santos, eu já havia tomado contato com esse formato pelas mãos da encenadora e pesquisadora Neyde Veneziano, na sua pesquisa de mestrado, por volta de 1988, que conseguiu colocar nas discussões acadêmicas o que a Revista Musical Brasileira, oriunda, em parte, da Revista Musical Portuguesa, tinha a sua dramaturgia e as suas convenções e, no texto do Cabaré da Santa essa estrutura estava lá presente e fortemente delineada.

Ao mesmo tempo, por formação, sempre estive ligado diretamente a conceitos musicais que foram transportados, também por gosto pessoal, ao meu trabalho dentro e fora do Folias, o que me permitiu dialogar com prazer pelo texto escrito desde o primeiro contato.

Esses, talvez, tenham sido os pontos de partida para as encenações.

HM: Primeiro o texto foi montado pelo Folias, no primeiro semestre de 2008; e naquele mesmo ano você foi para Coimbra e dirigiu o elenco português. Como encenador, quais os principais pontos com que você teve que lidar com os dois elencos? E quais as principais diferenças que você aponta nos resultados das duas montagens e suas respectivas apresentações?

DF: Bem... há muitos pontos em comum, porém diferenças também profundas. Valeria a pena citar como primeira diferença os orçamentos. $\mathrm{O}$ Folias foi contemplado com um edital público de montagem - PROAC, da Secretaria Estadual de Cultura do Estado de São Paulo - o que, pela primeira vez, me permitia como encenador ter um orçamento que continha, em suas rubricas, valores para uma melhor remuneração de todo elenco e equipe técnica, bem como para a produção total (cenários, 
figurinos, iluminação, sonorização... enfim...). Isso me permitiu, na encenação, conseguir colocar, por exemplo, a estrutura de cortinas da Revista Brasileira. Vale a pena ressaltar esse ponto. Como uma das convenções da Revista, há a presença de quadros de cortina (que são realizados na boca de cena) enquanto atrás dessa primeira cortina há uma troca de cenário, ou ambientação, para a próxima cena que será realizada. Há também uma terceira cortina que é aberta para a realização de números com maior número de atores e atrizes e esse jogo de abrir, fechar e levantar esse planejamento indica o ritmo que será dado à encenação. Foi possível, com esses recursos, fazermos duas apoteoses, outra convenção da Revista Brasileira, com direito a intervalo, fato não muito mais presente nas encenações da época. Esse mesmo orçamento também possibilitou toda a ambientação de "montar" um ambiente de bar que durante toda a encenação estava ativo com bebidas e aperitivos, com todo o serviço sendo realizado pelos atores e atrizes, reafirmando o sentido de divertimento que a dramaturgia continha.

O Teatrão, por outro lado, estava em um período que já prenunciava a grande crise que a Europa, e particularmente Portugal, sofreria. O orçamento era escasso e a Oficina Municipal de Teatro de Coimbra, sede da Companhia, sofria por reformas estruturais, tanto físicas, quanto administrativas, junto à Câmara da cidade. Isso fez com que, depois de várias e exaustivas discussões de produção (com Instituições Públicas) e artísticas internas (de corajosa resistência) chegássemos ao formato do espetáculo. O espetáculo em Coimbra estreou na TABACARIA da Oficina Municipal de Teatro, espaço que funciona no "foyer" da Oficina.

E diferentemente da montagem paulistana tinha a "mambembice" do fazer teatral escancarada, metateatralmente no seu formato. Uma cortina vazada escondia, supostamente, o ambiente onde o bar funcionava. $\mathrm{O}$ pequeno palco era, relativamente, pouco utilizado e as cenas aconteciam predominantemente em todo o espaço cênico da TABACARIA já existente. Não era uma ambientação de bar. Era o próprio bar. O espetáculo dava início com uma passagem do público pelo palco principal, em que atores e atrizes estavam terminando o cenário, literalmente verdadeiro no processo, e eram convidados a esperar no "foyer". A certo ponto, os espectadores eram informados de que o espetáculo não poderia ocorrer no palco principal e que aconteceria ali, no lugar da espera - a TABACARIA. Essa linguagem metateatral descortinava e espelhava tudo o que o Teatrão 
passava naquele momento de crise. Uma impossibilidade de estrear no espaço legalmente destinado a eles; e, também, todo o suor e a energia dispensados nos entraves burocráticos do local de estreia.

Talvez, como diferenças, esses pontos sejam os mais relevantes. Como ponto de aproximação, sem dúvida nenhuma, está a disponibilidade artística dos atores e atrizes e das equipes técnicas e artísticas. TODOS e TODAS, sem exceção, estavam verticalmente imersos naquelas empreitadas.

A vontade de colocar em cena o proposto pelas duas companhias irmãs foi, e é, até hoje o que permanece vivo em ambas.

Como relato pessoal gostaria de salientar uma curiosidade, ainda hoje enigmática para mim. Desde quando entrei em contato com o texto a figura da Santa Cecília me era provocativa. Existia uma vontade de que as imagens das Santas consideradas nacionais estivessem em cena: Nossa Senhora Aparecida do Brasil e Nossa Senhora de Fátima de Portugal. A imagem da Santa brasileira não foi para a cena. A imagem de Nossa Senhora de Fátima entrou nos ensaios no terceiro dia. Isso me faz refletir até hoje sobre a minha formação cristã (e da equipe brasileira) e a ideia da formação cristã que nós, os brasileiros, temos sobre o povo português. Sem nenhuma conclusão.

HM: Hoje, depois de mais de dez anos passados, como você avalia aquele projeto? Quais foram os saldos para os dois grupos e seus atores?

DF: Foi um projeto plenamente realizado, dadas as condições históricas daquele momento.

Os dois grupos conversaram, através das duas encenações.

Conversaram e continuam conversando até hoje.

$\mathrm{E}$, ao que parece, continuarão a conversar.

Permanece em ambos algo que, para os atores, me é muito caro - o encontro direto com a plateia. Isso se dá no conceito da TRIANGULAÇÃO presente até hoje em espetáculos que assisto de ambas as companhias.

A importância do ATOR-CRIADOR de Reinaldo Maia está presente nas interpretações dos atores e atrizes que estiveram nas duas montagens.

A interpretação épico-narrativa exposta no CABARÉ DA SANTA amplia até hoje o público que comparece às apresentações. 


\section{FICHA TÉCNICA:}

Concepção e realização da entrevista: Helder Mariani

Agradecimentos: Carlos Gontijo Rosa; Dagoberto Feliz; Jorge Louraço Figueira; Grupo Folias; Grupo Teatrão.

\section{APRESENTAÇ̃̃ES DO GRUPO FOLIAS}

Créditos: acervo do Grupo Folias

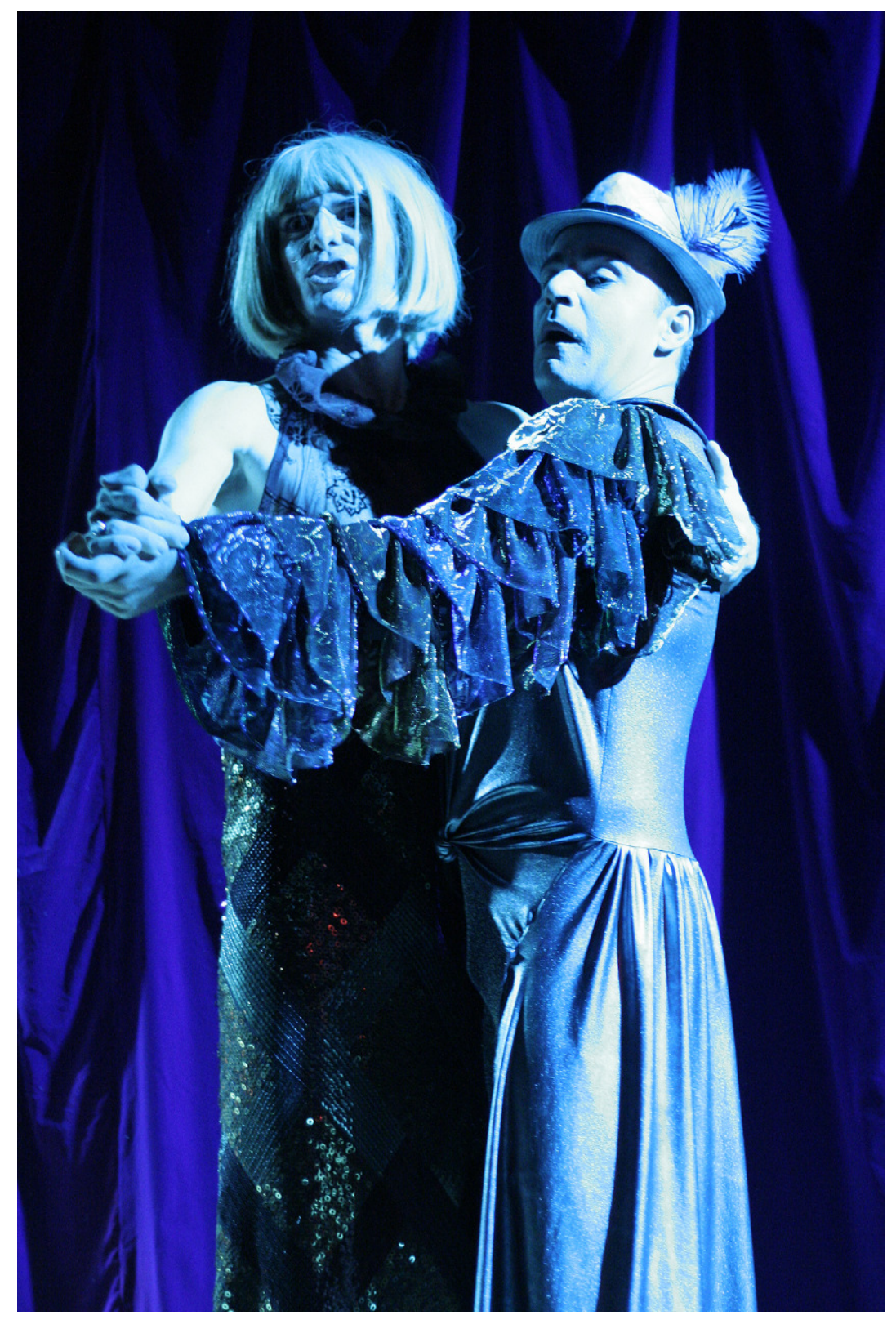


O FINGIMENTO NA DRAMATURGIA

\begin{tabular}{|l|l|l|l} 
VOLUME 12 NÚMERO 23 JUL/DEZ 2020 | ENTREVISTA &
\end{tabular}
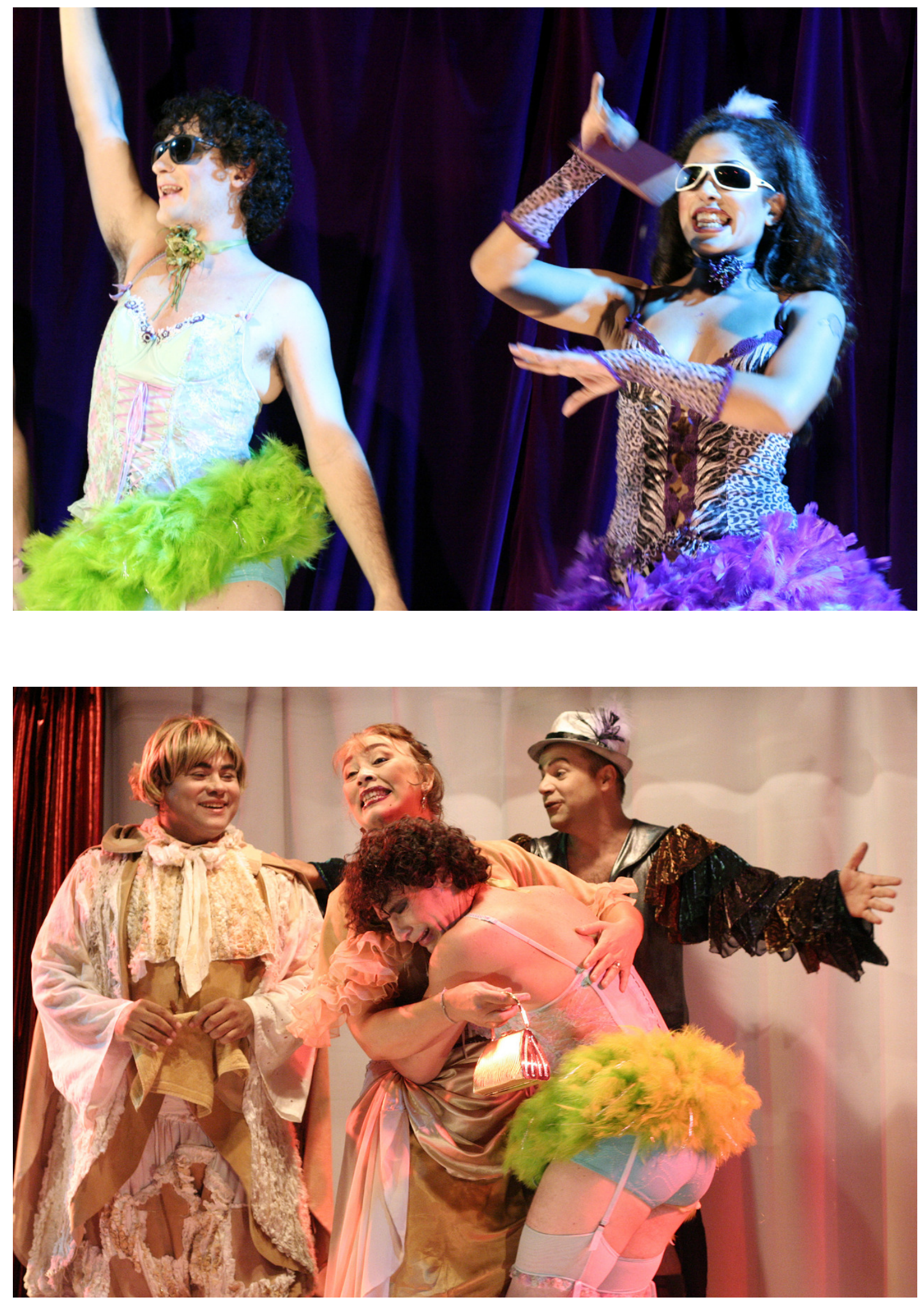
O FINGIMENTO NA DRAMATURGIA

\begin{tabular}{|l|l|l|l} 
VOLUME 12 NÚMERO 23 JUL/DEZ 2020 | ENTREVISTA &
\end{tabular}
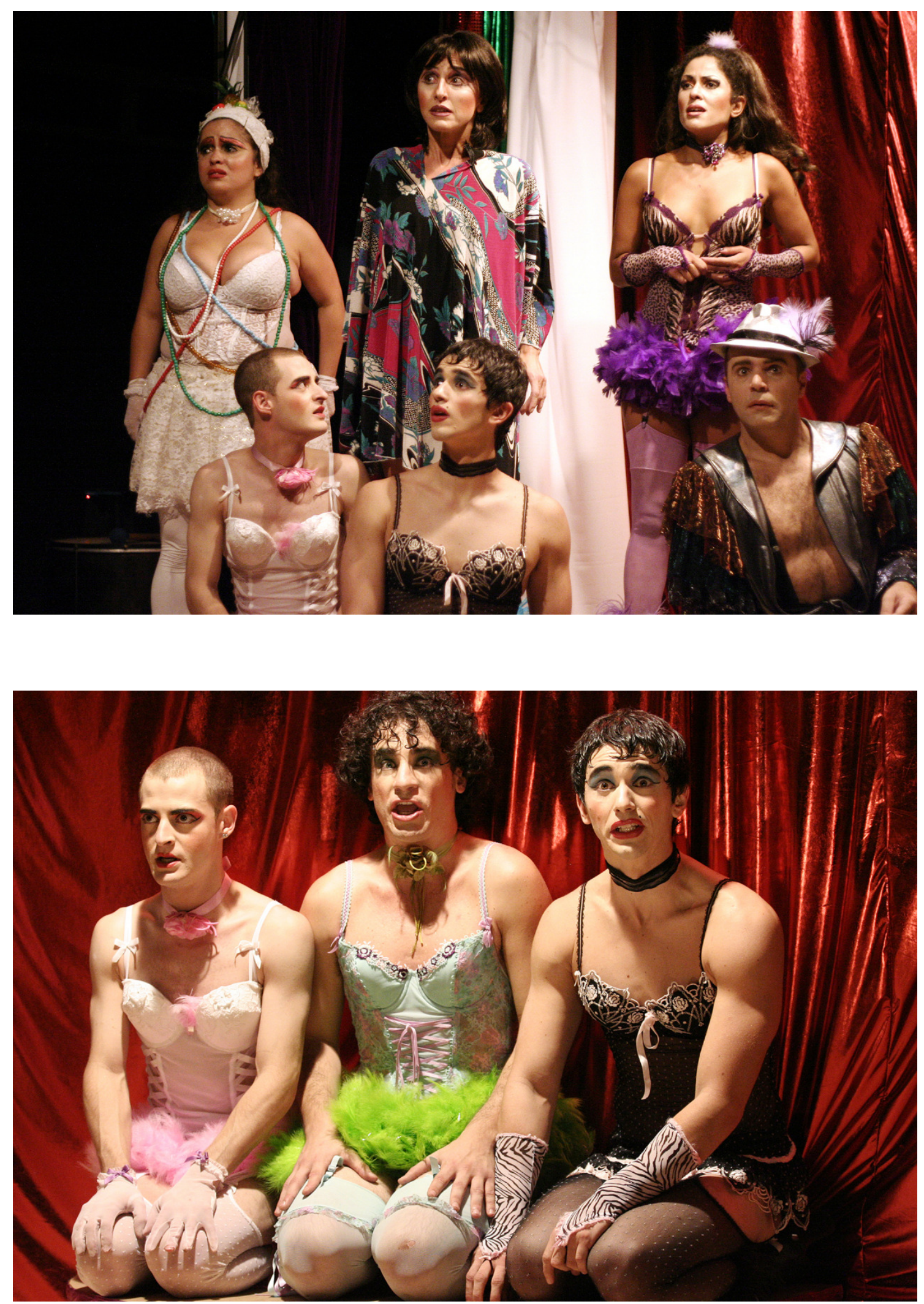


\section{APRESENTAC̄̃̃ES DO GRUPO TEATRÃO}

Créditos: acervo do Grupo Teatrão
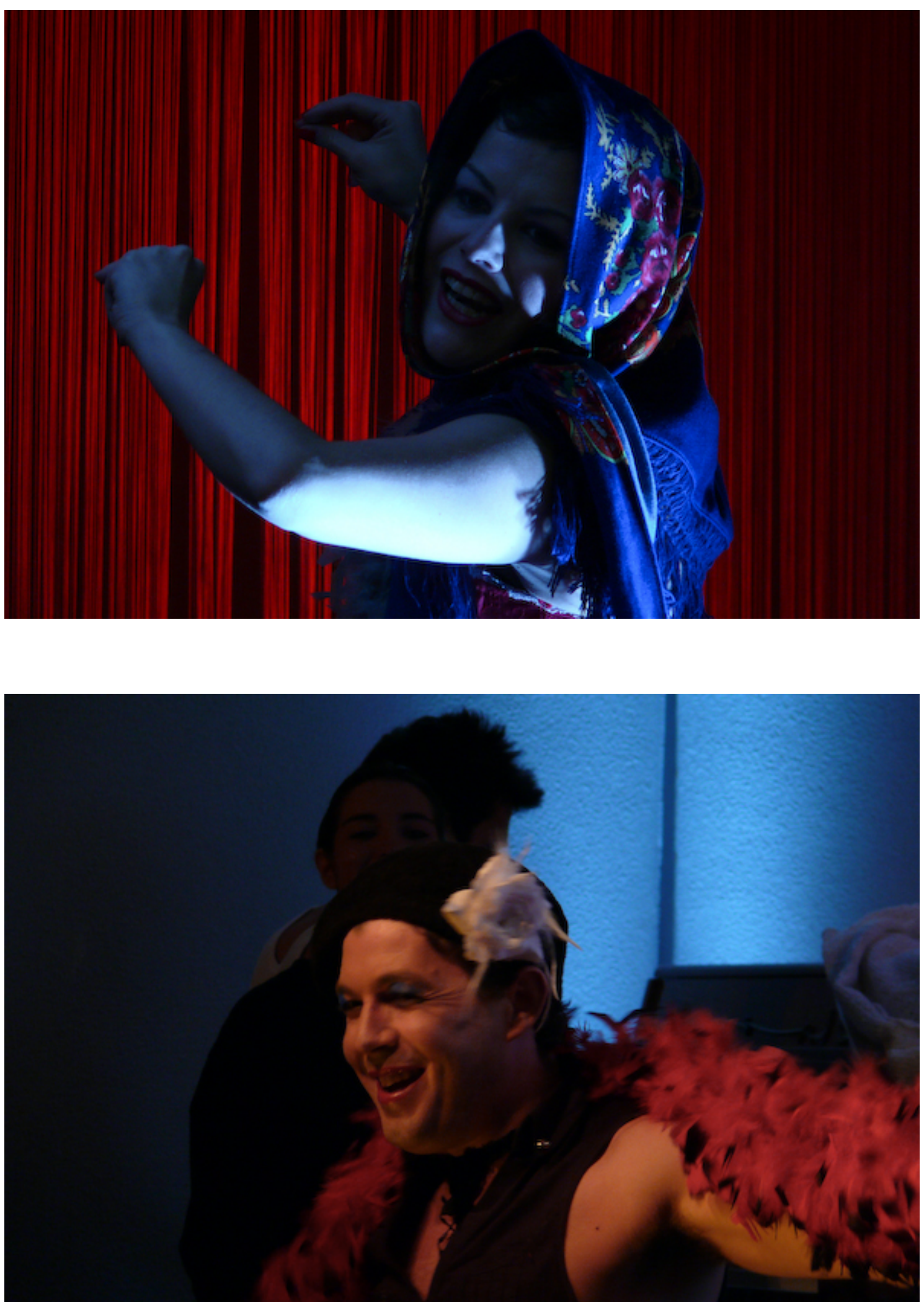
O FINGIMENTO NA DRAMATURGIA

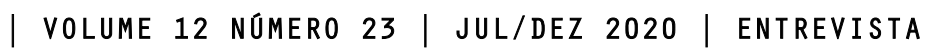
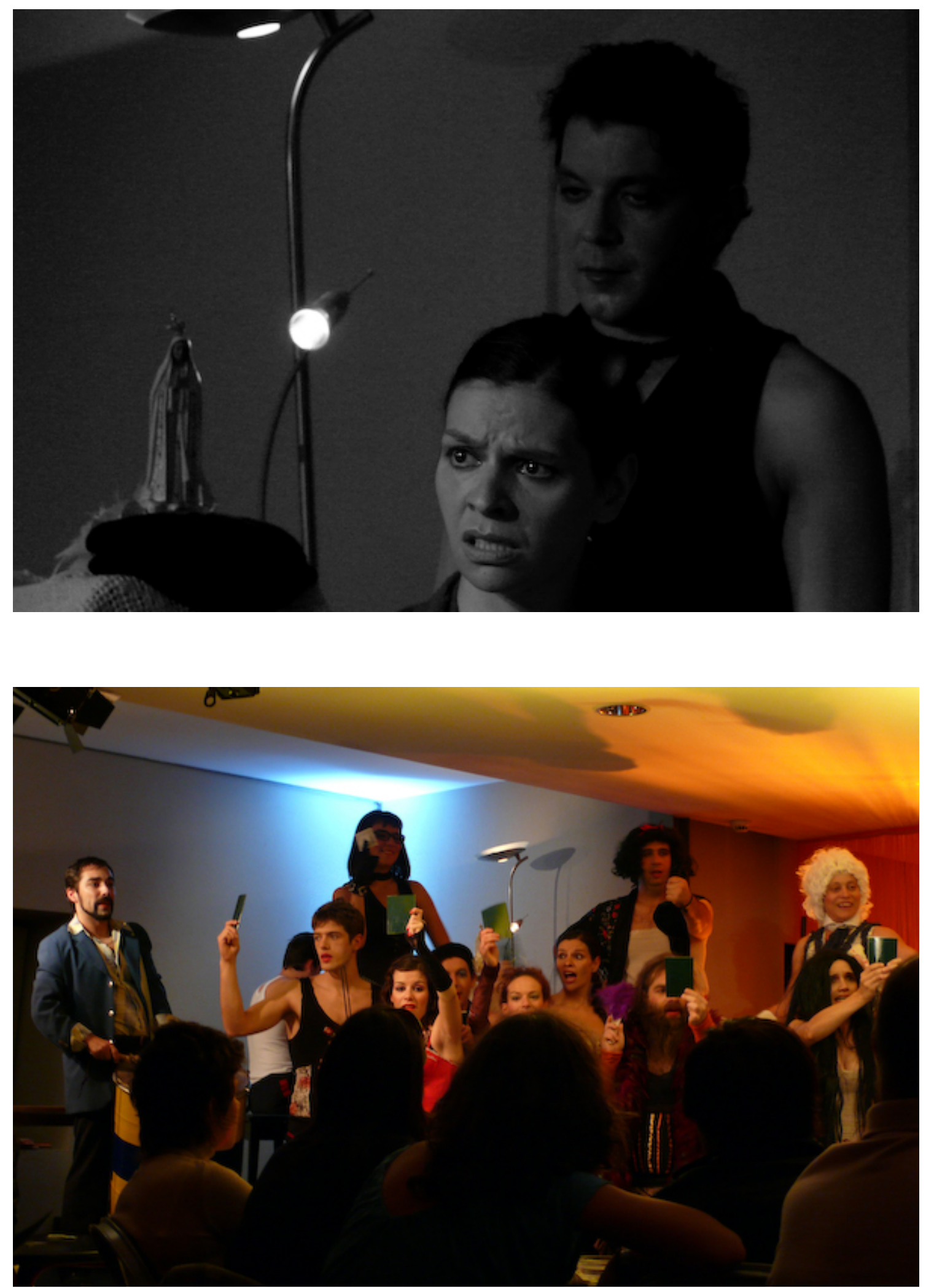
O FINGIMENTO NA DRAMATURGIA

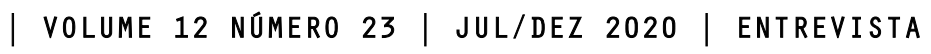
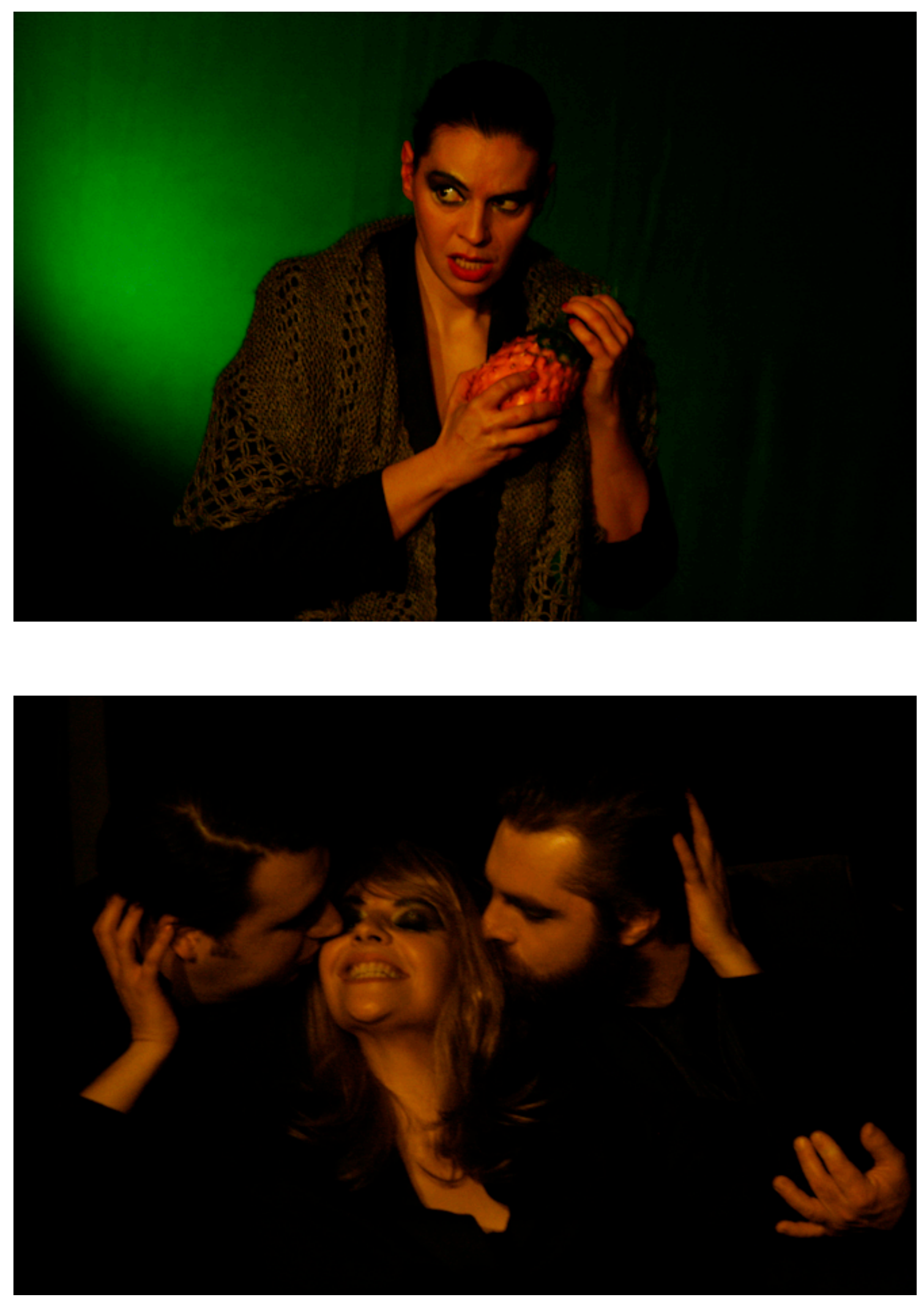


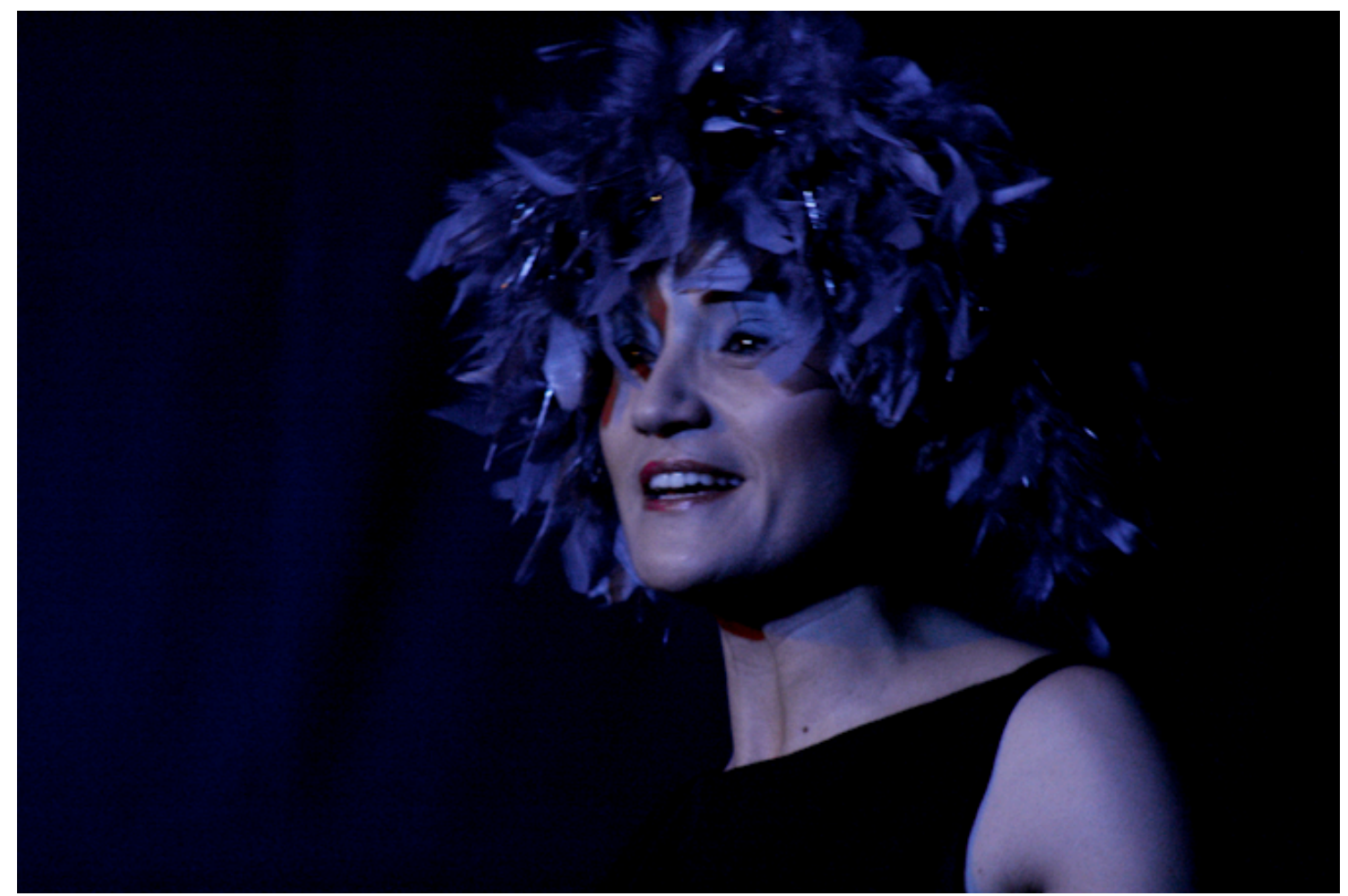

Recebido em 9 de novembro de 2020

Aprovado em 28 de novembro de 2020

\section{Licença: (ㄷ) (i) ()}

Helderson Mariani Pires

Em artes, Helder Mariani. Doutor e mestre em Filosofia pela Pontifícia Universidade Católica de São Paulo (PUC-SP). Especialista em Psicodrama pelo Instituto Bauruense de Psicodrama (IBAP). Bacharel em Direito pela Universidade de Ribeirão Preto (UNAERP).

Contato: heldermariani@terra.com.br 